ORBITAL IMPLANTS*

\title{
REVIEW OF RESULTS OBTAINED AT THE MOORFIELDS BRANCH OF THE MOORFIELDS, WESTMINSTER AND CENTRAL EYE HOSPITAL, LONDON
}

\author{
BY \\ D. P. CHOYCE
}

London

ENUCLEATION of an eye is likely to remain one of the commoner ophthalmic procedures. Out of approximately 4,000 operations performed at the Moorfields branch of the Moorfields, Westminster and Central Eye Hospital in 1950, 200 were for excision of an eye. A number of these were blind, painful eyes-thrombotic glaucoma, for example-in elderly people, in whom cosmetic considerations would be satisfied by an ordinary painted shell for the socket. These patients were commonly very grateful for the operation. Many of the remaining eyes were excised either after severe injury resulting in a disorganized and possibly dangerous globe, or for choroidal sarcoma. Here the patients not only lose what may well be a good seeing eye, but they are also much concerned with their post-operative appearance. Many of these patients are young, with their careers before them, and their future could well be affected by having an obviously false eye.

The recent war stimulated a great deal of work on movable ocular prostheses. Buried implants - of glass, ivory, and more recently of plastic material-impart an appreciable amount of movement to an overlying shell, provided that the muscles are sutured to or across the top of the implant. Nevertheless, recent work has moved away from the concept of the buried implant in favour of the integrated implant, in which the anterior surface is left exposed for direct contact with the painted shell (Reudemann, 1945 ; Cutler, 1947, 1949 ; Hudson, 1950 ; Stone, 1951). However, a search of the literature has failed to disclose any concrete statistics concerning the survival rate of these unburied implants. The nearest approach is contained in a personal communication from Stone (1951), who states :

136 post-enucleation implants have been placed during the past $3 \frac{1}{2}$ years. There have been no extrusions up to the present time. The implant is fashioned of methyl methacrylate and partially covered by a tantalum meshwork . . . there have been no infections behind the implant in the series.

This is a very remarkable achievement. It is not stated, however, how many of the 136 implants have been personally inspected by the surgeon concerned, and at what interval after insertion. Nor is it stated how many were placed 2 to 3 years ago and how many within the last 12 months.

Drucker and others (1951) reviewed the results obtained with both buried and unburied implants from the years 1946-1950, basing their remarks on

* Received for publication December 12, 1951. 
the answers to a questionnaire sent to four of the leading eye hospitals in the United States. The picture given is very different from that provided by Stone.

There were many practical difficulties in arriving at an accurate assessment of the results: owing to the migratory habits of the patients, only 50-60 per cent. of them were successfully traced; there was a wide variation in the details provided by the different institutions; and a large number of different types of implant were in use. Statistically, Drucker and others' results cannot be regarded as accurate. Nevertheless, certain statements in their paper stand out. For example :

Between March, 1946, and March, 1947, 23 (unburied) Cutler ring-type implants were inserted at the Wilmer Institute. Fifteen of the 21 primary implants were extruded on the average 6 months later; the remaining six were satisfactory after an average follow-up of 29 months.

Elsewhere in the paper it is stated that:

Troublesome secretion, recurrent granulations, and chronic infection were of common occurrence in surviving implants.

Experience with the buried implants (Hoffman, Allen, Troutman Magnetic) was on a much smaller scale, and none of the authors committed themselves in any way. It would appear, however, that extrusions were few, but that mobility was not so good as with the unburied implants.

\section{Scope of the Present Investigation}

By the end of 1950, 99 implants of varying types had been inserted at the Moorfields Branch of the Moorfields, Westminster and Central Eye Hospital. This number was made up as follows :

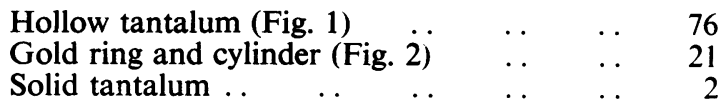

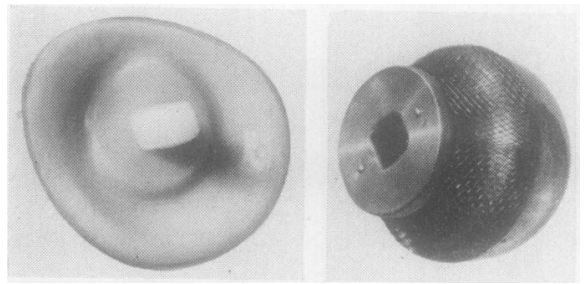

FIG. 1.-No. 13 tantalum implant. Posterior surface of mobileye showing peg.

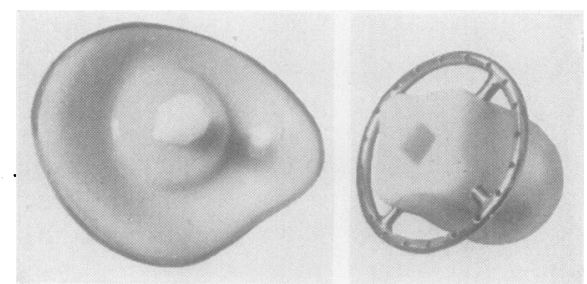

FIG. 2.-Gold ring and cylinder implant. Posterior surface of mobileye showing peg.

The anterior surface of all these implants was left exposed for direct contact with the posterior surface of the painted shell.

They have all been followed up to the end of 1951, so that none of the implants has been watched for less than 12 months. The following have been excluded from this survey : 
One solid tantalum implant worked out 10 months later and was replaced by a hollow tantalum implant.

One hollow tantalum implant used to replace a gold ring implant which was working out.

One gold ring implant used to replace a hollow tantalum implant which was working out.

One hollow and one solid tantalum implant placed inside the sclera after evisceration to which the muscles were not attached directly as was the case with the remaining implants under review.

One hollow tantalum implant introduced 20 years after enucleation of the eye for retinoblastoma.

Two gold ring implants in patients who died of metastases from choroidal sarcoma 6 months and 2 years respectively after operation. No information could be obtained about the state of the implant in these cases.

One gold ring implant and one hollow tantalum implant not able to be traced.

Excluding the above cases, there remain to be considered seventeen gold ring and 74 hollow tantalum implants. Altogether 98 per cent. of the total number of implants introduced have been successfully traced.

\section{Technique of Insertion of Implant}

A number of different operating surgeons have contributed to the cases here surveyed. Obviously, the operative technique varied in detail from surgeon to surgeon, but in all cases the principle remained the same, namely :

attachment of the four recti muscles to the gold ring or the tantalum mesh as the case might be, separate provision being made for Tenon's capsule and the conjunctiva.

Some surgeons carefully suture Tenon's capsule to the mesh and then the conjunctiva separately further up the mesh ; others disregard Tenon's capsule and merely suture the conjunctiva to the mesh; an even simpler technique is to suture the conjunctiva over the implant with a purse-string suture. The conjunctiva soon retracts and takes up an attachment to the mesh further back. Hudson (1950) splits the muscle tendons and unites half of each to half of its neighbour, leading to the development of a fibro-muscular ring round the neck of the tantalum implant and thus reducing still further the likelihood of a later extrusion of the implant.

However, the actual technique employed does not seem to matter much, if one is to judge by the results, since those of each surgeon approximate closely to those of his colleagues.

\section{Method of Conducting Survey}

The cases were divided according to whether or not the implant was still in situ. If not, the cause of loss was investigated; if so, the implant was examined as to movement, amount of discharge, presence or absence of granulations, and amount of mesh or gold ring exposed. An attempt was made to classify the implant as to prognosis as follows :

Grade 1.-The implant looked as though it should stay in indefinitely. This accolade was reserved for those cases in which no mesh or gold ring (as the case might be) was 
exposed, there was no discharge, there were no granulations, and there were good movements in all directions.

Grade II.-The implant looked as though it might stay in for another year or so. The criteria were the same as for Grade I, except that a moderate amount of discharge and some granulations were present and a small amount of mesh or gold ring was exposed.

Grade III.-The implant looked as though it would not be long before it either worked out or had to be removed. In this grade were placed implants in which much of the mesh or gold ring was exposed and there was considerable discharge and much granulation tissue.

Although this assessment is admittedly an arbitrary one, considerable importance is attached to this method of estimating the prognosis of implants, as will be seen later.

\section{Gold Ring and Hollow Tantalum Implants}

Immediate Results.-Most surgeons will agree that the immediate results of both types of implant are excellent. When an adequate painted shell has been fitted it takes an expert observer several seconds at least to determine which is the artificial eye, so good is the cosmetic result and so accurately do the movements of the prosthesis follow those of the sound eye. In a good case the implant moves fully in all directions, the excursion being limited only by the prosthesis impinging upon the orbital margin. The tiny " conversational" movements are present, and the implant may even converge when the sound eye accommodates for near objects. For ordinary social purposes these implants are more than adequate, and have been of great help in such occupations as teaching, where it is a considerable handicap to have an obviously false eye.

Having reviewed all these cases, I am of the opinion that while the gold ring implants tend to discharge less, the hollow tantalum implants have a better range of movement and look more normal, because the gold ring implant is smaller and gives the impression of a degree of enophthalmos when fitted with its painted shell. However, these are but minor points, and the immediate results of both types of implant are excellent.

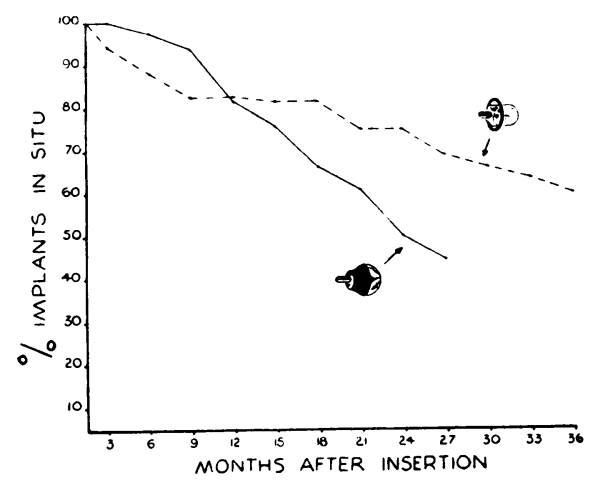

FIG. 3.-Survival rates of gold ring and hollow tantalum implants.

Delayed Results.-These can best be expressed graphically (Fig. 3). It will be seen that after the first 12 months there is a marked increase in the number of implants that come out. After 2 years, 75 per cent. of gold ring implants but only 50 per cent. of hollow tantalum implants were still in situ. As the number of gold ring implants reviewed was merely seventeen as compared with 74 of the hollow tantalum type, the difference of 25 per cent. in favour of the gold ring type cannot be regarded 
as statistically significant. The impression remains, however, that the gold ring implant stays in rather longer than the hollow tantalum type. By the end of 3 years, however, the percentage of gold ring implants remaining was reduced to 60 per cent.

Prognosis of Surviving Implants. - 26 hollow tantalum implants were reviewed 2 years after insertion, when thirteen were still in situ. The corresponding figures for the gold ring implants were twelve surviving out of sixteen. Table I illustrates the prognostic grading of the surviving implants according to the method oulined above.

In other words, out of $25 \mathrm{im}$ plants (thirteen hollow tantalum and twelve gold ring) still in situ 2 years after insertion, only five appeared to a critical judge to be

TABLE I

\begin{tabular}{l|c|c|c}
\hline $\begin{array}{c}\text { Type of } \\
\text { Implant }\end{array}$ & & \multicolumn{2}{|c|}{ Grade } \\
\hline Gold ring .. & I & II & III \\
\hline Hollow tantalum .. & 3 & 5 & 4 \\
\hline
\end{tabular}
likely to stay in indefinitely. Furthermore, the downward trend of both curves in Fig. 1 cannot be overlooked, and it would appear probable that 5 years after insertion only one or two implants at the most will still be in situ, the remainder having been rejected by the orbital tissues.

Causes of Loss.- 35 implants (five gold ring and thirty hollow tantalum) are known to have been extruded or to have been removed. The reasons for loss are summarized in Table II.

TABLE II

\begin{tabular}{|c|c|}
\hline Causes of Loss & No. of Cases \\
\hline $\begin{array}{l}\text { Chronic drug-resistant infection leading to gradual erosion of } \\
\text { attachment of implant .. } \\
\text { Constant drug-resistant infection without exposure of gold ring } \\
\text { or tantalum mesh } \\
\text { Recurrent acute orbital cellulitis involving long periods of } \\
\text { hospitalization } \\
\text { Haemorrhage behind implant on fifth post-operative day, infec- } \\
\text { tion of haematoma led to loss of implant after } 7 \text { months } . . \\
\text { Implant "worked out ", element of infection probably present. }\end{array}$ & $\begin{array}{r}21 \\
4 \\
2 \\
1 \\
7\end{array}$ \\
\hline
\end{tabular}

Some of these implants just " dropped" out, but the majority had to be removed surgically, which was quite an undertaking since so much dense fibrous tissue and haemorrhagic granulation tissue was present that a general anaesthetic was usually necessary. Biopsies of the socket lining in two cases failed to show any attempt at epithelialization.

Thus in 28 ( 80 per cent.) of the 35 cases, infection was primarily responsible for loss of the implant, and in the remaining 20 per cent. infection was probably a subsidiary factor. 
It was of interest to observe which part of the implant loosened first. In 90 per cent. it was the superior rectus attachment. The remaining 10 per cent. were divided between the internal and external recti. In no case did the inferior rectus give way initially; this phenomenon was so marked that one might consider leaving the inferior rectus unsutured, thus permitting it to form its own attachment to the implant. It is not clear why the superior attachment was the first to suffer in so many cases. Although the hollow tantalum implant and painted shell weigh about $6 \mathrm{~g}$., compared with $7 \mathrm{~g}$. for the average eye, yet gravity would presumably act more on the former than on the latter. The superior rectus is always weaker than the inferior and possibly the extra strain imposed by gravity is felt most by the weaker muscle, particularly when this is attached by fibrous tissue to the implant and not by its normal tendon to the sclera.

This investigation disclosed that the fate of the implant was not affected by certain likely factors, for example, the age of the patient, the reason for enucleation, or the particular surgeon who performed the operation. There was no evidence of electrolytic action leading to corrosion of the metal.

\section{Discussion}

The results disclosed by this survey cannot be regarded as satisfactory. If half the implants come out within 2 years and the remainder perhaps during the next 2 to 3 years, it can hardly be considered an economic procedure either from the patient's standpoint or as regards the best use of the available hospital beds. Ophthalmic surgeons should not rest until they have been able to improve substantially on this figure.

Analysis of the causes of loss of the implant suggests very strongly that a state of chronic infection exists in all these unburied implants and that this infection eventually causes loss of the implant. The conjunctiva is presumably never able to form a bacteria-proof junction with the foreign body with which it is in contact and is thus unable to fulfil its traditional anti-bacterial role with success. It would be reasonable to think that the incidence of infection would be much reduced and the implant's chances of survival proportionately increased if Tenon's capsule and the conjunctiva were separately united over the implant, thus burying it completely.

The reaction of tantalum with the tissues must also be considered. Carney (1942) was the first to show that it was well tolerated by the tissues. Pudenz (1943) studied the fate of tantalum plates in the skulls of cats, and demonstrated that they were relatively inert in this situation. Lewin and others (1948) reported on 124 cases where tantalum plates were used to repair skull defects in war casualties. After 2 years, 94 were completely satisfactory, and eleven had been removed, including five for infection. The incidence of infection, both early and late, was 7 per cent. One would conclude from these figures that the continued use of tantalum plates in this situation would be justified. 
Douglas (1948) reports on the use of tantalum gauze in the repair of large herniae, with good results, and Schultz and Fowler (1947) recommend its use in the cheek and lips, but McLaughlin (1949) reported failure in every case where tantalum wire was used in cases of facial palsy. He ascribed fragmentation of the wire to :

(a) electrolytic action between the wire and neighbouring metallic dental fillings, with consequent corrosion of the tantalum,

(b) alteration in the crystalline structure of the metal owing to continual stresses in the wire, such as would be caused by passive facial movements as in eating.

Parallel research has been going on into the use of acrylic resin (methyl methacrylate). Beck and others (1945) inserted acrylic disks into rabbits' skulls and noted very little reaction. Small and Graham (1945) reported on 25 cases where acrylic disks were used to repair skull defects in man, and in 24 the immediate results were satisfactory.

However, even if 50 per cent. hollow tantalum implants came out after two years, 50 per cent. stayed in, and in spite of the lack of certainty concerning the inertness of tantalum in the tissues, it would appear justifiable to proceed with buried tantalum implants. At the suggestion of Mr. F. A. Williamson-Noble, Messrs Theodore Hamblin Limited have constructed several different prototypes (Fig. 4), some of which have already been inserted, so far with results immediately satisfactory. One such case was shown at a recent meeting of the Ophthalmic Section of the Royal Society of Medicine.

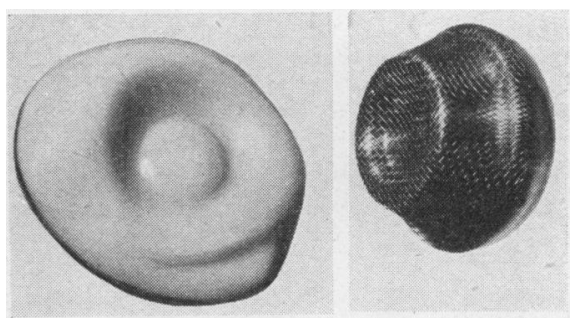

Fig. 4.-No. 14 tantalum implant for burying, note dimple on anterior surface. Posterior surface of mobileye showing nipple.

Tantalum is expensive, each implant costing $19-10$, and in the interests of economy an effort should be made to develop an acrylic implant which would lend itself to this type of operation as readily as do the tantalum implants. Messrs John Weiss and Son Limited make one to the specif.cation of Castroviejo, but no reports are available of its use in Great Britain.

\section{Summary}

(1) 98 per cent. of all the orbital implants inserted at the Moorfields Branch of the Moorfields, Westminster and Central Eye Hospital up to the end of 1950 have been followed up.

(2) 50 per cent. of the hollow tantalum implants came out after 2 years and 40 per cent. of the gold ring after 3 years. The prognosis of the surviving implants is reviewed and it is considered probable that only one or two implants at the most will be in situ 5 years after insertion.

(3) The predominant factor causing loss of these implants was found to be infection. It is considered that the infection was largely due to the fact that these implants were not completely buried.

(4) The position of tantalum and acrylic implants in plastic surgery is reviewed. 
(5) It is suggested that the use of all unburied orbital implants be abandoned and that henceforth only buried implants either tantalum or acrylic be used.

(6) An interval of at least 3 years after insertion should elapse before the value of any new type of orbital implant is assessed.

My thanks are due to the Medical Committee of the Moorfields Branch of the Moorfields, Westminster and Central Eye Hospital for permission to peruse the hospital records and to publish the results of this investigation ; to Dr. P. Hansell of the Department of Medical Illustration, Institute of Ophthalmology, for the graph and photographs ; to Messrs Theodore Hamblin Ltd. for their co-operation; and to Miss White of the Registrar's Department at the Moorfields Branch, through whose efforts such a high percentage of the patients was successfully traced.

\section{REFERENCES}

Beck, D. J. K., Russell, D. S., Small, J. M., and Graham, M. P. (1945). Brit. J. Surg., 33, 83. Carney, H. M. (1942). Proc. Soc. exp. Biol., N.Y., 51, 147.

Cutler, N. L. (1947). Arch. Ophthal., Chicago, 37, 73. (1949). Amer. J. Ophthal., 32, 253.

Douglas, D. M. (1948). Lancet, 1, 936.

Drucker, A. P., Kreft, W. W., Pearlman, M. D., Rosenau, J. A., and SniP, R. T. (1951). Amer. J. Ophthal., 34, 1483.

Hudson, J. R. (1950). British Journal of Ophthalmology, 34, 251.

Hughes, W. L. (1948). Amer. J. Ophthal., 31, 303.

Lewin, W., Graham, M. P., and NorthCroft, G. B. (1948). Brit. J. Surg., 36, 26.

Mclaughlin, C. R. (1949). Lancet, 1, 255.

Pudenz., R. H. (1943). J. Amer. med. Ass., 121, 478.

Ruedemann, A. D. (1945). Trans. Amer. ophthal. Soc., 43, 304.

Schultz, L. W., and Fowler, E. F. (1947). Plast. reconstr. surg., 2, 538.

Small, J. M., and Graham, M. P. (1945). Brit. J. Surg., 33, 106.

STONE, W. (1951). Personal communication. 